\title{
A PROPOSTA BILÍNGUE NA EDUCAÇÃO DE SURDOS: PRÁTICAS PEDAGÓGICAS NO PROCESSO DE ALFABETIZAÇÃO NO MUNICÍPIO DE COLORADO DO OESTE/RONDÔNIA
}

\author{
M. C. F. F. MORET ${ }^{1}$ e J. G. RODRIGUES ${ }^{2}$ \\ Universidade Federal de Rondônia \\ marcia.moret@ifro.edu.br ${ }^{1}$
}

Artigo submetido em 17/05/2019 e aceito em 11/12/2019

DOI: $10.15628 /$ holos.2019.5933

\section{RESUMO}

O ensino da língua portuguesa faz parte do currículo escolar regular e seu domínio estabelece uma relação com a sociedade, constituída pela maioria de ouvintes. Nesse ponto existe a preocupação da educação dos surdos, que estão concluído o ensino médio sem saber ler e/ou produzir na língua portuguesa. Essa problemática afeta o desenvolvimento social desses sujeitos, uma vez que a língua portuguesa é sua segunda língua e LIBRAS sua língua materna. Esse conflito mostra que o aluno surdo é incluído nas escolas regulares, mas sem o direito a uma educação bilíngue, que dispõe o ensino e uso da Libras nas aulas. Essa pesquisa de cunho bibliográfico tem como objetivo mostrar a eficácia da proposta bilíngue no processo de alfabetização dos surdos e proporcionar mais oportunidades e qualidade no processo educacional, uma vez que o oralismo e o bimodalismo/comunicação total não foram capazes de sanar a problemática quanto à alfabetização.

PALAVRAS-CHAVE: Bilinguismo, Alfabetização, Libras.

\section{INTRODUCTION TO THE STUDY OF DEAF EDUCATION: FROM THE ORALISM TO THE BILINGUAL PROPOSAL IN THE PROCESS OF LITERACY}

\section{ABSTRACT}

The teaching of the Portuguese language is part of the regular school curriculum and its command provides a relationship with the society that is formed mostly of hearing. At this point, there is a concern of the deaf education, who are concluding high school without knowing how to read and/or produce texts in Portuguese. This problem affects the social development of these subjects, since the Portuguese is their second language and their mother tongue is the Brazilian Sign Language (LIBRAS). This conflict shows that deaf students are included in regular schools, but without the right to bilingual education, which offers the teaching and use of LIBRAS in class. This bibliographic nature research aims to show the efficiency of bilingual proposal on deaf literacy process and offer more opportunities and quality in the educational process, since the oralism and bimodal bilingualism / total communication were not able to solve the problem with the literacy.

KEYWORDS: Bilingualism, Literacy, Brazilian Sign Language (LIBRAS). 


\section{INTRODUÇÃO}

A educação dos surdos no Brasil é reconhecida dentro do cenário da inclusão escolar, que segundo Sassaki (1997, p. 81) postula uma reestruturação do sistema de ensino, com o objetivo de fazer com que a escola se torne aberta às diferenças e competente para o trabalho com todos os educandos, sem distinção de raça, classe, gênero ou características pessoais.

Ao longo da trajetória da educação dos surdos é visível as batalhas e consequentemente as conquistas adquiridas por eles, mas sabe-se que ainda há muito a ser feito.

Durante a história, essa educação passou por duas fases importantes até chegar à fase atual: a primeira foi à fase Oralista, que tinha como objetivo a recuperação dos surdos, ou seja, a tentativa de fazer com que os surdos se comunicassem oralmente, não sendo permitidos a esses usar a língua de sinais. Acreditava-se que essa "recuperação" seria a solução para a surdez, pois com a proibição do uso de sinais e do gestual nos ambientes, os surdos teriam que começar a falar para conseguir se comunicar com os demais.

A segunda fase foi o Bimodalismo ou Comunicação Total como também é conhecida, que permitia o uso da língua de sinais e a oralidade ao mesmo tempo. Essa fase tinha como objetivo principal o ensino da Língua Portuguesa. Dessa forma o ensino era pautado na estrutura gramatical da língua portuguesa, sendo transmitido aos surdos não a língua de sinais e sim o português sinalizado. Nesse caso desrespeitando a língua materna do surdo.

O português sinalizado nada mais é, do que sinalizar cada palavra citada e respeitar a estrutura frasal/sentença da língua portuguesa.

Segundo Quadros (2008, p. 26) o oralismo e o bimodalismo ainda estão sendo desenvolvidos nas escolas brasileiras, porém com todo o sofrimento e prejuízo essa educação começou a ser vista com um novo olhar e novas buscas para a transição da atual fase que é a proposta educacional bilíngue (Bilinguismo).

Essa luta da comunidade surda para implantação da proposta da educação bilíngue nas escolas brasileiras é devido ao fato das duas fases anteriores não terem atingido sucesso e acarretado prejuízos na educação dos surdos. Essa nova fase da educação tem como objetivo uma educação de qualidade, sendo transmitidos aos surdos os conteúdos na sua primeira língua (L1) Língua de Sinais - LIBRAS e a Língua Portuguesa (L2) sendo sua segunda língua ensinada em momentos específicos. Essa proposta já é garantia em Lei desde 2005, mas percebe-se que ainda não está sendo utilizada/implantada nas escolas brasileiras.

No contexto escolar atual essa educação ainda é uma utopia, uma vez que:

A criança surda é colocada em contato com a escrita do português para ser alfabetizada em português seguindo os mesmos passos e materiais utilizados nas escolas com as crianças falantes de português. Várias tentativas de alfabetizar a criança surda por meio do português já foram 
realizadas, desde a utilização de métodos artificiais de estruturação de linguagem até o uso do português sinalizado (QUADROS; SCHMIEDT, 2006, p. 23)

Isso faz com que o aluno surdo perca o direito já conquistado na Lei, que é uma educação bilíngue. Nessa abordagem Quadros \& Schimiedt (2006, p.143) aponta que os surdos têm o direito de serem alfabetizados com a Libras, sua primeira língua e o português como segunda língua, para ter a possibilidade de interagir com os ouvintes e toda a sociedade. Vale ressaltar que os surdos usuários da Libras, devem priorizar sua língua, mas não desprezar a Língua Portuguesa, uma vez que está também é importante para seu desenvolvimento social e sabendo que o mundo a sua volta é usuário da língua portuguesa. Outro fato relevante é a viabilidade no processo educacional e na sua formação, pois precisam produzir textos, artigos, prestar concursos, Enem e outros, e na maioria das vezes o intérprete não pode traduzir todo o enunciado da avaliação, sendo possível só tirar dúvidas de algumas palavras. Assim se não domina a leitura/escrita terá dificuldade e possivelmente não obterá êxito nos resultados dessas etapas.

Deve-se ainda ressaltar que a Libras não poderá substituir a modalidade escrita da língua portuguesa como já citado no parágrafo único da Lei 10.436/02, isso porque é uma língua visualmotora e sua escrita ainda é pouco difundida no Brasil e ainda gera muitas pesquisas.

Muitos acreditam que os surdos não precisam aprender a escrita/leitura do português uma vez que já temos no Brasil o sistema de escrita de sinais o Signwriting, que é possível escrever qualquer sinal, em qualquer língua de sinais, ou seja, ele funciona como um sistema de escrita universal. "Nele as características das línguas de sinais são preservadas e os parâmetros fonológicos e sintáticos são descritos fielmente" (BARRETO \& BARRETO, 2012), porém esse sistema ainda não é ensinado nas escolas e é pouco difundido até mesmo entre os surdos. Geralmente são usados em escolas especializadas para surdos com classes bilíngues.

Segundo Dallan \& Mascia (2010, p. 4):

O sistema SignWriting foi desenvolvido pela norte-americana Valerie Sutton, por volta da década de 70, quando estava na Universidade de Copenhague, na Dinamarca, grafando balés tradicionais através de um sistema criado por ela para esta finalidade, o DanceWriting. Sutton despertou a atenção de pesquisadores da língua de sinais Dinamarquesa na Universidade de Copenhague, que viram naquela escrita uma possibilidade para notação dos sinais utilizados na comunicação/interação das pessoas que fazem uso desta língua visual. Surgia então, na Dinamarca, o primeiro movimento para grafar as línguas de sinais. De sistema escrito à mão, passou-se a um sistema possível de ser escrito no computador, com um programa, o Signwriter, criado dentro do próprio movimento Sutton para grafia das línguas visuais.

As línguas de sinais não são línguas ágrafas, ou seja, elas possuem alguns sistemas de escrita, tal como as línguas orais. Segundo Gesser (2009, p. 42) "até bem pouco tempo, a língua de sinais era considerada uma língua sem escrita". No entanto devido ao atraso e a exclusão dessa língua na sociedade, houve um atraso muito grande na criação da sua escrita e até nos dias atuais é uma luta da comunidade surda para essa efetivação. Sendo assim torna-se imprescindível a aquisição da língua portuguesa, pois o surdo precisa se expressar de forma escrita, ou seja, por no 
papel sua ideias e como no país a língua oficial é a língua portuguesa, ele precisa desse conhecimento.

Quando falamos na importância do aprendizado da língua portuguesa é para deixar o indivíduo surdo no mesmo princípio de igualdade, pois vemos o sofrimento destes nas etapas de ensino, nas etapas de concorrência em vagas de emprego e outros. Sabe-se que o mundo a nossa volta é letrado e o surdo pertence a esse mundo. Assim é preciso oportunizar esse ensino de forma correta, onde ele possa ter a aquisição das duas línguas: visual-gestual e escrita/leitura.

Refletindo sobre a educação do sujeito surdo, é evidente que existirá indagações quanto ao êxito no processo educacional, pois se é cobrado uma língua na qual eles não dominam e que não faz parte da sua identidade surda, logo haverá dificuldades e obstáculos a serem superados por esses alunos. "A identidade surda, aqui refere-se à maneira como os surdos definem a si mesmo, ou seja: de forma cultural e linguística" (SÁ. 2010. p.15).

Ainda seguindo a autora Sá (2010.p.314) nossa identidade é formada pela fusão de elementos de diversos sistemas culturais, e esse entendimento deveria ajudar a considerar os valores e instrumentos da cultura surda. Mas a grande preocupação é que as crianças surdas são cobradas nas pautas culturais ouvintes e isso nos leva a refletir sobre a educação dos surdos em nosso Estado, principalmente na etapa da alfabetização, que consequentemente se estende por todo o ensino regular e médio. A língua portuguesa deve ser ensinada e cobrada como segunda língua do sujeito surdo pautando-se na educação bilíngue.

Em pesquisa na CRE (Coordenadoria Regional de Educação) da cidade de Vilhena/RO, que é responsável pelo município de Colorado do Oeste, verificou-se que a maioria dos alunos tem concluído o ensino médio sem saber ler e/ou produzir na língua portuguesa.

Tem-se vivido em um século com muitas mudanças, e no que se refere à educação de surdos e a inclusão, precisamente nas escolas estaduais da área urbana, da cidade de Colorado do Oeste, essa pesquisa foi singular, pois ainda encontramos surdos analfabetos no ensino médio, além da falta de formação profissional para o ensino desses alunos que estão avançando de série sem qualidade da sua educação. Assim essa pesquisa buscou identificar os métodos utilizados no processo escolar desses alunos, buscando promover mudanças nessas práticas pedagógicas com a aplicação da proposta bilíngue nesse processo. Isso possibilitou o desenvolvimento da aprendizagem da língua escrita padrão junto a aluna surda participante da pesquisa.

A escola por sua vez tem a missão de respeitar esses alunos com necessidades específicas, uma vez que fazem parte da diversidade que segundo Gomes (2007, p.18) é "um componente do desenvolvimento biológico e cultural da humanidade". Ela se faz presente na produção de práticas, saberes, valores, linguagens, técnicas artísticas, científicas, representações do mundo, experiências de sociabilidade e de aprendizagem" Dessa maneira o processo educacional dos surdos ocorrerá com sucesso, dando lhes uma verdadeira alfabetização e preparo para o futuro. Vale ressaltar que todas essas práticas pedagógicas bilíngues devem estar previstas no Projeto Político Pedagógico da escola, para que seja assegurado aos surdos o direito primeiramente ao acesso a Língua Natural, nomeada como L1, precedida pela Língua oral, utilizada na comunidade a qual o surdo pertence, nomeada como L2, pois esta teoria acredita que para se aprender uma segunda língua, ele precisa antes, dominar a sua própria língua. Convém salientar que a "escola é 
um espaço privilegiado" (SÁ. 2010.p. 312) e se utilizado dos métodos propostos nesta teoria, garantirá aos alunos seus direitos previstos na Lei e acima de tudo "garantirá o desenvolvimento da cultura surda"(SÁ. 2010.p. 312).

O interesse por está pesquisa se dá de forma pessoal e profissional, uma vez que no decorrer de minha trajetória estudantil e profissional surgiram inquietações quanto à problemática da alfabetização dos surdos.

Durante meu tempo de trabalho, percebi as dificuldades dos surdos quanto à língua portuguesa e a progressão nas séries iniciais do ensino fundamental, apesar do aluno não estar alfabetizado na língua portuguesa, terminando até mesmo o ensino médio sem saberem ler ou produzir em português.

Eles alunos conseguem e tem domínio no conteúdo somente na sua língua, mas muitas vezes se prejudicam nas avaliações por não saberem o português e assim não conseguem expressar a resposta escrita.

Devemos pensar que o mundo a nossa volta é usuário da língua portuguesa e que esses alunos devem ter a noção da leitura e da escrita uma vez que os ajudará nessa convivência com o mundo letrado.

Atualmente em um projeto de extensão desenvolvido pela pesquisadora no Instituto Federal de Rondônia, Campus Colorado do Oeste, a mesma problemática veio à tona, pois os professores participantes do projeto tinham a mesma angústia quanto à escolarização desses alunos, surgindo então o convite para a pesquisa-ação na Escola Estadual de Ensino Fundamental e Médio Manuel Bandeira, aplicando a proposta bilíngue na alfabetização de uma aluna surda matriculada no 10 ano do ensino médio e que ainda não está totalmente alfabetizada.

O interessante é que em uma cidade com cerca de 18.338 habitantes segundo censo do IBGE (2012) que possui 12 escolas públicas que oferece ensino fundamental e médio e que tem 2.658 matrículas no ensino fundamental e 1.148 matrículas no ensino médio, ter somente uma aluna surda matriculada no ensino médio nos causa espanto e nos faz questionar onde estão os jovens surdos que não estão matriculados nas escolas da cidade? Quantos abandonaram a escolarização pela falta de inclusão? Quantos saíram da escola com a mesma problemática que é a falta de ensino de qualidade?

Essas indagações nos leva a refletir quanto ao nosso papel de educadores e formadores de cidadãos capazes de expressar sua opinião, críticos e, sobretudo cidadãos de lutam pela melhora do nosso país e de seus direitos.

Sabendo-se que esses sujeitos têm sua própria cultura, que existe mais de um método pedagógico que permeia essa trajetória e que são pessoas que por anos se sentiram excluídas, até mesmo das pessoas próximas, só por causa da falta de comunicação, do direito de ser e estar no meio social, sujeito esse conhecido muitas vezes erroneamente como surdo-mudo.

A problemática é que a prática da teoria bilíngue nas escolas regulares ainda não é comum, o que leva muitos profissionais a defender a ideia equivocada sobre a escolarização desses sujeitos. Nesse contexto pretendemos com a pesquisa-ação responder as seguintes questões: $O$ trabalho em parceria entre professor(a) do AEE (Atendimento Educacional Especializado), Intérprete de 
Libras, subsidiado pela pesquisadora que tem a formação em LIBRAS, desenvolvido junto a aluna surda pode evidenciar a eficácia da proposta bilíngue? Ela promove o desenvolvimento efetivo da aprendizagem da língua portuguesa?

Estes questionamentos fazem parte da busca por uma solução e poderão ser pensadas e sanadas através da presente pesquisa, pois conduzirá possíveis mudanças, onde a pretensão é agir junto com a comunidade surda, buscando a aplicação real da proposta bilíngue na escolarização dos alunos surdos. Assim tornar a educação mais acessível e igualitária, dando os mesmos direitos e deveres a esses cidadãos.

A pesquisa foi desenvolvida na rede estadual de ensino, uma vez que esses alunos após o término do ensino fundamental ou médio poderão adentrar nos campi do IFRO, trazendo consigo essa problemática da alfabetização. Quanto ao critério de abordagem da pesquisa, será realizada uma pesquisa-ação de forma qualitativa, uma vez que se preocupa com aspectos da realidade que não podem ser quantificados.

\section{REVISÃO BIBLIOGRÁFICA}

A educação para surdos vem ganhando destaque ao longo da história, pois passa por várias lutas e conquistas. Uma das conquistas mais relevantes adquiridas por eles é o reconhecimento da língua sinais - LIBRAS através da Lei no 10.436/02 onde profere no Art. 1 "É reconhecida como meio legal de comunicação e expressão a Língua Brasileira de Sinais - Libras e outros recursos de expressão a ela associados". Seguindo em parágrafo único complementa:

Entende-se como Língua Brasileira de Sinais - Libras a forma de comunicação e expressão, em que o sistema linguístico de natureza visual-motora, com estrutura gramatical própria, constituem um sistema linguístico de transmissão de ideias e fatos, oriundos de comunidades de pessoas surdas do Brasil" (BRASIL, 2002).

Quando falamos na educação do surdo é preciso um conhecimento mais aprofundo sobre todo o processo histórico desse assunto.

A educação dos surdos passou por duas fases muito importantes até chegar à fase atual. A primeira fase foi à educação oralista, que tinha como objetivo a "recuperação" dos surdos, ou seja, uma reabilitação da fala, fazer o surdo se comunicar através da língua oral, " o oralismo não permite que a língua de sinais seja usada nem mesmo em sala de aula nem no ambiente familiar, mesmo sendo esse formado por pessoas surdas usuárias da língua de sinais"(QUADROS, 2008, pg.22).

Um outro problema do oralismo está relacionado à questão da aquisição da língua oral, pois "o surdo é capaz de captar somente $20 \%$ só capita do que é falado, além de não ser 
compreendido por pessoas que não convivem com ele diariamente" (QUADROS, 2008, p.23). Sabese que esses surdos precisam treinar a fala, ter acompanhamento de fonoaudiólogos para melhorar à dicção e sua oralidade e deixar a prioridade que é a comunicação através da língua de sinais e isso fez com que o oralismo não fosse aprovado pela comunidade surda, pois limitava a forma de expressão do sujeito surdo.

Segundo Quadros (2008, p.26) "o oralismo é considerado pelos estudiosos como a imposição social de uma maioria linguística (os falantes das línguas orais) sobre uma minoria linguística sem expressão diante da comunidade ouvinte (os surdos)" e também afirma que "'o oralismo sempre foi e continua sendo uma experiência que apresenta resultados nada atraentes para o desenvolvimento da linguagem e da comunidade dos surdos (2008, p.22).

Sacks (1990, p. 45) diz que "o oralismo e a supressão do sinal resultaram numa deterioração dramática das conquistas educacionais das crianças surdas e no grau de instrução do surdo em geral. Muitos dos surdos hoje em dia são iletrados funcionais". Assim os surdos perdem as condições de competir em seus pares ouvintes, não sendo possível ter o mesmo rendimento.

A Federação Nacional de Educação e Integração dos Surdos (FENEIS) realizou uma pesquisa que aponta que $5 \%$ da população surda total estudante das universidades são incapazes de lidar com o português escrito (FENEIS, 1995, p.7).

Dessa forma percebe-se que essa fase da educação dos surdos acarretou diversos problemas para vida social e educacional desses sujeitos, pois não foi possível transmitir o conhecimento necessário, trazendo consigo a problemática da falta do domínio da língua portuguesa escrita para os dias atuais.

A segunda fase se constituía pelo bimodalismo ou comunicação total como também era chamada, proposta essa que:

Permite o uso da língua de sinais com o objetivo de desenvolver a linguagem da criança, mas sendo usado como recurso para o ensino da língua oral'. Os sinais passam a ser usados junto com a língua portuguesa, mas na estrutura da língua portuguesa. (QUADROS, 2008. p. 24).

O bimodalismo é um sistema artificial considerado inadequado tendo em vista que desconsidera a língua de sinais e sua riqueza estrutural e acaba por desestruturar também o português (QUADROS, 2008, p.26)

O ensino não enfatiza o oral, mas sim o bimodal, as sinalizações são feitas simultaneamente a fala, mas toda estrutura utilizada é da língua portuguesa. Sacks (1990) citado por Ferreira Brito (1993) criticam essa proposta, pois dizem ser inviável o ensino de duas línguas diferentes ao mesmo tempo, sendo essa ineficaz para a alfabetização do surdo:

Não é possível efetuar a transliteração de uma língua falada em sinal palavra por palavra, ou frase por frase, as estruturas são essencialmente diferentes.[...] e, no entanto, os surdos são obrigados a aprender os sinais não para ideias e ações que querem expressar, mas pelo sons fonéticos[..] que não podem ouvir (SACKS,1990, p.47). 
Quando falamos nessa fase educacional é preciso ter conhecimento das diferenças nas estruturas gramaticais das duas línguas e conseguir percebe-las nas formas de expressão.

Quando sinalizamos e falamos ao mesmo tempo, não pensamos em LIBRAS e sim em português. Isso significa que fazes um português sinalizado.

Essa proposta é bem criticada, pois há impossibilidade de preservar as estruturas das duas línguas ao mesmo tempo. Ferreira Brito (1993) salienta que as expressões faciais e movimentos utilizados na língua de sinais nem sempre são possíveis de serem usados concomitantemente com a fala, pois existem sinais que são feitos na boca. Nesse caso como sinalizar e falar ao mesmo tempo? Não é possível, provando assim que o bimodalismo é inviável.

Na língua portuguesa a entoação é um elemento muito importante da frase falada, pois nos dá uma ampla possibilidade de expressão, depende dessa entonação, por exemplo para sabermos se a frase é interrogativa, exclamativa, negativa, afirmativa ou imperativa, ou se for escrita precisa da pontuação. Já na língua de sinais isso é feito seguindo os parâmetros da língua e um dos parâmetros que mostra a intenção da frase é a expressão.

Oliveira (1995) argumenta que a língua de sinais possui cinco parâmetros de sinalização que são fundamentais para o processo de comunicação e expressão, descrito a seguir.

1- CONFIGURAÇÃO DAS MÃOS: são formas das mãos, que podem ser da datilologia (alfabeto manual) ou outras formas feitas pela mão predominante (mão direita para os destros), ou pelas mãos do emissor ou sinalizador. Os sinais APRENDER, LARANJA e ADORAR têm a mesma configuração de mão;

2- PONTO DE ARTICULAÇÃO: é o lugar onde incide a mão predominante configurada, podendo esta tocar alguma parte do corpo ou estar em um espaço neutro vertical (do meio do corpo até a cabeça) e horizontal (à frente do emissor). Os sinais TRABALHAR, BRINCAR e CONSERTAR são feitos no mesmo espaço neutro e os sinais ESQUECER, APRENDER e PENSAR são feitos na testa;

3- MOVIMENTO: os sinais podem ter um movimento ou não. Os sinais citados acima têm movimentos, com exceção de PENSAR que, como os sinais AJOELHAR, EM-PÉ, não têm movimentos;

4- ORIENTAÇÃO: os sinais podem ter uma direção e a inversão desta pode significar ideia de oposição, contrária ou concordância número - pessoal, como os sinais QUERER e QUERER - NÃO; IR e VIR;

5- EXPRESSÃO FACIAL E/OU CORPORAL: muitos sinais além dos quatro parâmetros mencionados acima têm como traço diferenciador também a expressão facial e/ou corporal, em sua configuração. É o caso dos sinais ALEGRE e TRISTE. Há sinais feitos somente com a bochecha, como LADRÃO, ATO - SEXUAL. 
Segundo Quadros (2008, p. 26) existe parâmetros comuns entre a língua de sinais e a língua portuguesa, mas sem duvidas há parâmetros diferentes, pois se não seriam a mesma língua, sendo assim não é possível serem usados ao mesmo tempo.

Assim podemos afirmar que "o bimodalismo/comunicação total não foi e não será uma proposta adequada para a escolarização dos surdos" (QUADROS, 2008, p. 26), pois se percebeu ao longo do uso dessa proposta que os alunos continuaram com a defasagem no aprendizado do português: escrita e leitura e também para o aprendizado dos conteúdos escolares.

Com toda essa problemática, ineficácias e prejuízos à educação dos surdos, ganha um novo despertar, uma nova perspectiva e se inicia a transição para a terceira fase da educação de surdos: o bilinguismo, que está sendo visto com a "salvação" para educação dos surdos, que até hoje foram prejudicados pelas fases anteriores, pois nenhuma estava obtendo êxito na alfabetização e no seu desenvolvimento. Essa proposta objetiva a melhoria na educação do surdo, uma vez que respeita a autonomia das línguas de sinais, língua materna do surdo a L1.

A proposta bilíngue segundo Quadros (2008. p.32 e 33) "é trabalhar todos os conteúdos na língua nativa das crianças surdas", ou seja, LIBRAS e trabalhar a língua portuguesa momentos específicos das aulas com leitura e escrita da língua.

Com o surgimento do Bilinguismo, é priorizado a Língua de Sinais como sua primeira língua e a Língua Portuguesa como segunda língua, não fala mais de limitações, mas sim de novas possibilidades. Vê a Língua de Sinais como seu maior meio de concretizar a aprendizagem, dessa forma pode-se deduzir que a oferta de oportunidade educacional sempre favorece para a melhoria do desenvolvimento linguístico dos surdos e isso é imprescindível para a evolução de cada um deles.

A proposta bilíngue garante ao aluno o acesso aos conteúdos curriculares na sua língua materna "LIBRAS" e diz que: "o aluno precisa garantir a aquisição da língua de sinais, bem como da língua portuguesa em contextos educacionais distintos" (LODI, 2015, p. 50) sendo ensinados com base em metodologias utilizadas para o ensino de uma segunda língua. Essas metodologias partem das habilidades interativas e cognitivas já adquiridas pela criança surda diante de suas experiências com LIBRAS. Dentro dessa concepção bilíngue é criado um ambiente apropriado para o processo de ensino/aprendizagem, respeitando as duas línguas L1 e L2 e assegurado o pelo desenvolvimento da criança surda, pois oportuniza o acesso completo aos conteúdos curriculares.

O bilinguismo vem se destacando atualmente na educação de surdos justamente por se tratar de uma "Proposta" que respeita a diversidade e a pluralidade cultural desses alunos, buscando de forma geral sua formação completa.

No bilinguismo deve se atentar também com a questão cultural, pois os surdos possuem sua cultura surda e estão em contato direto com a cultura ouvinte do país, dessa forma precisa se pensar numa proposta bilíngue bicultural. Respeitando as duas culturas existentes no meio, tornando possível essa troca cultural e sobretudo "[...] respeitar a pessoa surda e sua condição sociolinguística implica considerar seu desenvolvimento pleno como ser bicultural a fim que possa dar-se em um psicolinguístico normal"' (SKLIAR, 1995, p. 16).

A proposta bilíngue é a mais indicada para alfabetização do surdo, uma vez que levará os 
conhecimentos específicos em Língua de Sinais. Nessa proposta os materiais devem ser adaptados pelo professor em parceria com o tradutor/intérprete de LIBRAS, devem ser inseridas imagens ao lado das palavras chaves do texto, usar vocabulários escritos com imagens, matérias lúdicos e visuais, além de utilizar as experiências que o aluno já possui em LIBRAS. Lembrando sempre que o surdo é visual e precisa desse recurso para sua aprendizagem. "O trabalho pedagógico requer muita flexibilidade e criatividade dialógica sinalizada, sempre reafirmando a importância da compreensão da cultura surda existente" (VILHALVA, 2007, p.1).

Por recomendação do MEC, o ensino de surdos no Brasil precisa ser:

"(...) efetivada em língua de sinais, independente dos espaços em que o processo se desenvolva. Assim, paralelamente às disciplinas curriculares, faz-se necessário o ensino de língua portuguesa como segunda língua, com a utilização de materiais e métodos específicos no atendimento às necessidades educacionais" (BRASIL, et al; 2004 p. 47).

Para esse trabalho de alfabetização é importante ressaltar que "o professor precisa conhecer a cultura desse aluno [...] conhecer a cultura surda através da participação e vivência na comunidade surda, aceitação da diferença e paciência para inteirar - se nela" (VILHALVA, 2007, p.1).

Ainda segundo Vilhalva (2007) a alfabetização de alunos surdos é um choque tanto para o professor ouvinte como para os alunos surdos, por não entenderem de imediato o complexo linguístico da língua um do outro, dessa forma não é um processo simples e exige uma dedicação e formação para tal processo.

Para que a formação bilíngue ocorra, é indicado que haja um instrutor surdo responsável por ensinar e transmitir a cultura surda juntamente com a LIBRAS, trabalhando em conjunto com o professor bilíngue, ouvinte.

A necessidade do ensino da segunda língua, em sua forma escrita, se baseia na estreita relação existente entre cidadania e competência comunicativa e sabe-se que o sujeito surdo se depara com a demanda constante de produzir, ler e até de comunicar de forma escrita, pois temos uma minoria de ouvintes que sabem língua de sinais. Também pelo fato de precisarem se locomover, viajar, prestar um concurso, ENEM e outros que necessitam da leitura e escrita. Assim Karnopp (2005, p.59) afirma que "o acesso à palavra (em sinais e na escrita) é traduzido como uma forma de acesso das pessoas ao mundo social e linguístico, sendo condição mínima e necessária para que o aluno possa participar efetivamente da aula, entendendo e fazendo-se entender", ficando evidenciado a importância do surdo conhecer o português (L2).

A importância da palavra sinalizada e escrita está então, na possibilidade da comunicação sobre si.

Importante ressaltar que os professores que trabalham com surdos, também precisam conhecer a sua língua, isso porque para se ensinar o português o professor precisa conhecer LIBRAS. Nesse sentido Karnopp (2007, p.68) afirma que: "o conhecimento da Língua de Sinais pelo professor é um requisito primordial para a efetivação de práticas pedagógicas que considerem a 
diferença linguística e cultural dos surdos".

\section{METODOLOGIA}

Segundo Thiollent (1996, p.7) o desenvolvimento das metodologias aplicadas na pesquisaação pode vir a desempenhar um importante papel nos estudos e na aprendizagem dos pesquisadores e de todas as pessoas ou grupos implicados em situações problemáticas.

Quando se fala em pesquisa-ação um dos principais objetivos "é dar aos pesquisadores e grupos de participantes os meios de se tornarem capazes de responder com maior eficiência aos problemas da situação em que vivem, em particular sob forma de diretrizes de ação transformadora" (THIOLLENT,1996, p.8). Nesse contexto pode-se afirmar que é a pesquisa-ação é a busca por soluções aos problemas reais e que devido à urgência de tais problemas, "os procedimentos a serem escolhidos devem obedecer a prioridades estabelecidas a partir de um diagnóstico da situação na qual os participantes tenham voz e vez"(THIOLLENT,1996, p.8). Dessa forma a pesquisa precisa ter como principal objetivo a resolução dos problemas da sociedade e;

Para que não haja ambiguidade, uma pesquisa pode ser qualificada de pesquisa-ação quando houver realmente uma ação por parte das pessoas ou grupos implicados no problema sob observação. Além disso, é preciso que a ação seja uma ação não-trivial, o que quer dizer uma ação problemática merecendo investigação para ser elaborada e conduzida (THIOLLENT,1996, p.8).

O ciclo desta pesquisa foi dividido em cinco etapas e deve como meta a resolução do problema encontrado quanto à alfabetização da aluna surda.

Ainda de acordo com Thiollent (1996);

O objetivo da pesquisa-ação é principalmente voltado para a produção de conhecimento que não seja útil apenas para a coletividade considerada na investigação local. Trata-se de um conhecimento a ser cotejado com outros estudos e suscetível de parciais generalizações no estudo de problemas sociológicos, educacionais ou outros, de maior alcance. A ênfase pode ser dada a um dos três aspectos: resolução de problemas, tomada de consciência ou produção de conhecimento (THIOLLENT,1996, p.9).

A primeira etapa foi a realização de um diagnóstico sobre a escolarização da aluna surda, cuja finalidade era identificar a etapa de alfabetização em que se encontrava e assim poder elaborar um plano de ação para o trabalho com a mesma. Esse diagnóstico foi realizado através da aplicação do instrumental Provinha Brasil, reconhecido pelo MEC (Ministério da Educação e Cultura) que tem como objetivo a verificação do nível de alfabetização de alunos matriculados no segundo ano de toda rede pública brasileira e assim buscar por melhorias e sanar o analfabetismo.

A segunda etapa consistiu-se na elaboração do plano de ação individual com a participação da professora do AEE e da Intérprete de LIBRAS que acompanha a estudante nas aulas. O plano 
elaborado contém: atividades destinadas á alfabetização de pessoas surdas embasadas na proposta bilíngue, cujas estratégias serão pautadas no ensino e avaliação de uma segunda língua sendo esta a língua portuguesa.

A terceira etapa foi a execução do plano de ação, que acorreu em 2 (dois) bimestres, sendo aplicada a pesquisa todas as sextas-feiras, no período vespertino que é o oposto ao que a aluna estuda, no horário das $14 \mathrm{~h}$ às $17 \mathrm{~h}$.

A quarta etapa foi a nova aplicação do Instrumental Provinha Brasil, que teve como objetivo a verificação da aprendizagem da aluna a ser comparada com a primeira etapa da pesquisa.

A quinta e última etapa foi a análise dos resultados obtidos durante toda a pesquisa, apontando assim os avanços durante a aplicação da proposta bilíngue e suas estratégias.

Sendo assim, o presente estudo tem como objetivo geral analisar os avanços e retrocessos a partir da intervenção do professor do AEE e intérprete junto ao processo de alfabetização de surdo na perspectiva bilíngue.

Para atingir tal objetivo, delineou-se a pesquisa por meio dos seguintes objetivos específicos: (a) diagnosticar o planejamento do professor do AEE; (b) diagnosticar o nível de escolarização da aluna surda; (c) estruturar o planejamento conjunto entre professor do AEE e intérprete a partir da proposta bilíngue; (d) estruturar ações de intervenção a partir de uma proposta bilíngue para alfabetização de surdo; (e) executar ações de intervenção; (f) identificar as principais dificuldades enfrentadas no processo de intervenção; (g) avaliar o nível alcançado de alfabetização a partir da aplicação da proposta bilíngue.

Quanto ao critério de abordagem da pesquisa, foi realizada uma pesquisa qualitativa, uma vez que se preocupa com aspectos da realidade que não podem ser quantificados. Minayo (2012) afirma que uma pesquisa que se caracteriza como abordagem qualitativa, é aquela que responde questões particulares nas ciências sociais.

\section{RESULTADOS E DISCUSSÕES}

A Escola E.E.F.M. Manuel Bandeira no ano de 2016 tinha 523 alunos matriculados, destes somente 14 alunos necessitavam do atendimento do AEE.

Quando se iniciou a pesquisa-ação foi realizado o levantamento dessa demanda, e para surpresa da pesquisadora somente uma era DA (Deficiência Auditiva) os outros 13 alunos eram DI (Deficiência Intelectual).

O trabalho na sala do AEE com esses alunos sempre ocorre em período oposto ao que estudam, uma vez na semana com duração de 2 horas, conforme prevê o Artigo 5ㅇ da Resolução no 4 de 02 de outubro de 2009:

O AEE é realizado, prioritariamente, na sala de recursos multifuncionais da própria escola ou em outra escola de ensino regular, no turno inverso da escolarização, não sendo substitutivo às classes 
comuns, podendo ser realizado, também, em centro de Atendimento Educacional Especializado da rede pública ou de instituições comunitárias, confessionais ou filantrópicas sem fins lucrativos, conveniadas com a Secretaria de Educação ou órgão equivalente dos Estados, Distrito Federal ou dos Municípios.

No caso específico da aluna surda, ela vai mais de uma vez por semana na escola no período oposto ao que está matriculada. Isso porque tem atendimento com a Intérprete de LIBRAS que realiza um trabalho voltado para o ensino da sua língua materna LIBRAS, já que a mesma não tem contato com seus pares e porque a escola ainda não possui um instrutor surdo para esse ensino, também ensino da Língua Portuguesa, além de apoio na realização dos trabalhos solicitados em sala de aula.

Durante o pesquisa foi necessário um trabalho voltado para formação docente, uma vez que a professora e a Intérprete não possuem conhecimentos a cerca da proposta bilíngue na educação de surdos. Esse trabalho foi realizado em 2 (dois) encontros onde foram explicados os fundamentos da proposta bilíngue para alfabetização dos surdos, a elaboração das atividades bilíngues, conceito sobre a cultura surda e o processo de ensino-aprendizagem para esses alunos. Essa formação específica para professora do AEE e intérprete foi de grande relevância, pois elas dão suporte aos demais docentes que atuam com a aluna surda na escola.

A pesquisa foi dividida em cinco etapas sendo descrita de forma narrativa, a fim de evidenciar as intervenções, dificuldades e avanços no decorrer do processo.

A pesquisa teve duração de dois bimestres sendo esses o terceiro e o quarto do ano letivo de 2016.

\section{1a ETAPA}

Para o início da pesquisa foi necessário à aplicação do instrumental Provinha Brasil que tinha como objetivo de diagnosticar o nível de alfabetização da aluna.

Essa aplicação foi de suma importância uma vez que não seria possível se trabalhar com a aluna desconhecendo o nível de sua alfabetização.

O instrumental escolhido "Provinha Brasil" foi pensado, pois não seria necessário a criação de um novo instrumental de avaliação, se já temos um tão eficiente e criado pelo MEC para averiguação justamente do nível de alfabetização dos estudantes brasileiros.

O instrumental sendo aplicado em alunos do $2^{\circ}$ ano do ensino fundamental não seria muito simples para uma aluna matriculada no 10 ano do ensino médio? Seria se a mesma não tivesse dificuldades com a escrita/leitura da língua portuguesa. Mas como em conversas anteriores com a intérprete da escola que já havia apresentado as dificuldades dessa aluna, foi optado por esse instrumental, pois de forma sucinta poderíamos evidenciar o nível de sua alfabetização.

Para aplicação do instrumental foi utilizada a sala do AEE da escola, juntamente com a equipe da sala. Na oportunidade foi explicado a aluna como seria o desenvolvimento da pesquisaação e questionado seu interesse de participação nessa pesquisa. A aluna expressou seu interesse e disse estar feliz, pois reconhece a importância de aprender o português para seus estudos e até mesmo para se comunicar com ouvintes não usuários da LIBRAS. 
No início da aplicação da avaliação, já se percebeu a dificuldade da aluna através do seu olhar, que sempre buscava a intérprete de LIBRAS que a acompanha nas aulas, olhar esse de socorro. No momento pensei que pudesse ser nervosismo ou vergonha. Pedi que se calmasse e avisei que se tivesse dúvidas, poderia perguntar. Também foi explicado que esse trabalho não seria para prejudica-la, pelo contrário ajudá-la na melhoria da escrita e da leitura.

Durante a aplicação da avaliação percebeu-se que a aluna não conseguia entender o que o enunciado solicitava, tão pouco conseguia ler os pequenos textos da avaliação. Nesse momento não restou alternativa e precisei traduzir toda a avaliação em LIBRAS, afim de que a mesma conseguisse responder a avaliação.

Após a avaliação foi feito agradecimento à aluna pela participação e dispensou-se a mesma nesse dia.

A equipe do AEE juntamente com a pesquisadora iniciou a correção e análise da avaliação, chegando à conclusão quanto que o nível da alfabetização da aluna era o silábico-alfabético.

Para analisar o nível de alfabetização foi necessária uma reflexão na teoria da psicogênese da língua escrita de Ferreiro (1986) que afirma que "toda criança passa por quatro fases até que esteja alfabetizada"' (FERREIRO, 1986, p.26).

Baseados nessa teoria de Ferreiro (1986) a equipe colaborativa e a pesquisadora chegaram ao consenso que a aluna encontra-se no nível silábico-alfabético.

\section{2a ETAPA}

Nessa etapa da pesquisa foi elaborado um plano individual de trabalho para aluna surda, uma vez que o plano já existente na sala do AEE não contemplava a necessidade da aluna e nem se baseava na proposta bilíngue.

$\mathrm{Na}$ oportunidade foram desenvolvidas diversas atividades para serem aplicadas no decorrer da pesquisa-ação e explicado a equipe como proceder dentro dessa proposta.

Essas atividades estão pautadas na proposta bilíngue, pois são utilizadas LIBRAS, imagens e a língua portuguesa e sua metodologia é de ensino de segunda língua.

Essa construção foi realizada de forma colaborativa com equipe do $A E E$, uma vez que darão sequência a esse trabalho.

\section{3a ETAPA}

Nessa etapa foi realizado todo o trabalho de ensino da língua portuguesa para a aluna surda, usando a metodologia de ensino de uma segunda língua, baseada na proposta bilíngue.

Nessa etapa houveram diversas intervenções e também obstáculos como qualquer ação que envolva o processo de ensino-aprendizagem. Esse processo teve início de terceiro bimestre letivo de 2016 e concluiu-se no quarto bimestre letivo de 2016.

Com já apresentado anteriormente, precisou-se realizar uma formação continuada para as colaboradoras da pesquisa, uma vez que não tinham conhecimento nessa proposta de ensino para surdos.

Após essa formação iniciou-se o trabalho com a aluna, que por sua vez estava no nível silábico-alfabético. 
O processo de ensino aprendizagem da aluna se deu com a aplicação de diversos materiais elaborados pela pesquisadora e equipe do AEE baseados no bilinguismo.

Esse material foi construído usando imagens, libras e português escrito e objetivo de facilitar a assimilação da escrita e leitura da L2.

Durante a pesquisa ocorreram alguns percalços, um deles foram diversos atrasos da aluna aos encontros. Esses atrasos ocorreram devido à necessidade da aluna usar insulina para controlar a diabetes. Ela precisava se recuperar dessa medicação para então se deslocar para escola. 0 trajeto era realizado a pé, e como nosso clima Rondoniense é quente, a aluna ficava com fraquezas para ir no período da tarde para escola. Ocorrem algumas faltas também, mas a intérprete colaboradora aplicava na semana seguinte às atividades propostas, para que não houvesse perca da aluna e nem atraso da pesquisa.

As atividades elaboradas começaram com textos pequenos e ensino dos vocabulários básicos do texto, conforme figura a baixo, ou conhecidos como palavras chaves do texto, que foram trabalhados em mais de um encontro.

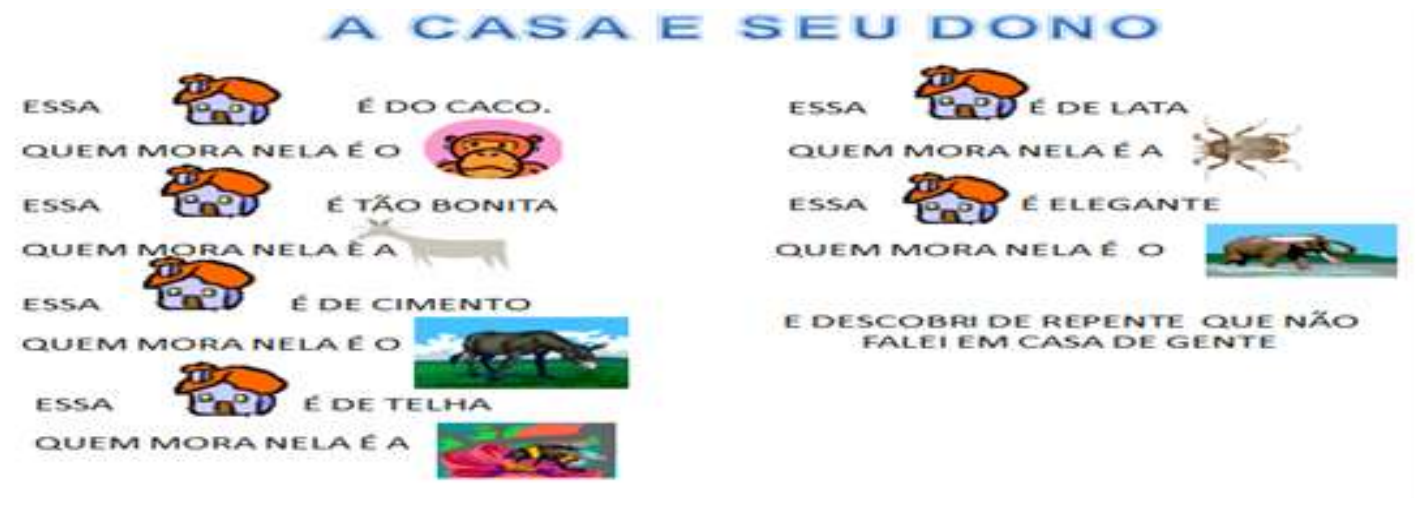

Figura 01- Texto baseado na proposta bilíngue.

Fonte: Moret (2016)

Um fato relevante a ser exposto é que, não era dado sequência para outra atividade caso a aluna não tivesse aprendido de fato.

O trabalho se iniciava com a explicação do texto em libras e em seguida apresentado em português. Eram apresentadas as palavras chaves do texto em forma de vocabulário, explicado a significação de cada palavra e utilizado da outras atividades para fixação do aprendizado dessas palavras. Nessa etapa precisou-se trabalhar os significados das palavras para que a aluna fizesse a assimilação e fixação quando tinha a correspondência entre escrita e imagem.

Foram utilizados: jogo da memória, atividades de ligar, colagem, caça-palavras, complete, cruzadinha, junção das sílabas e outros.

Para conclusão de cada atividade e certeza do aprendizado da aluna, era trabalhado um ditado em libras ou ditado de imagens para que a mesma transcrevesse para o português cada sinal ou imagem.

As atividades elaboradas foram ganhando complexidade conforme o desenvolvimento da aluna durante a pesquisa. 
À medida que se percebia a evolução da aluna, era elaborado textos maiores e de maior complexidade. Além de oferecer a aluna vocabulários livres e dirigidos para verificação do nível de aprendizado da mesma.

Nos vocabulários livres e dirigidos à aluna só escreve o que tem conhecimento, porém é dado ajuda na escrita dos textos. Simplificando isso: a aluna escreve na forma da cultura surda, sem o uso de: artigos, preposições e os verbos no infinitivo e a professora ajuda na reescrita da história usando esses componentes gramaticais da língua portuguesa.

Abaixo o exemplo da afirmação:

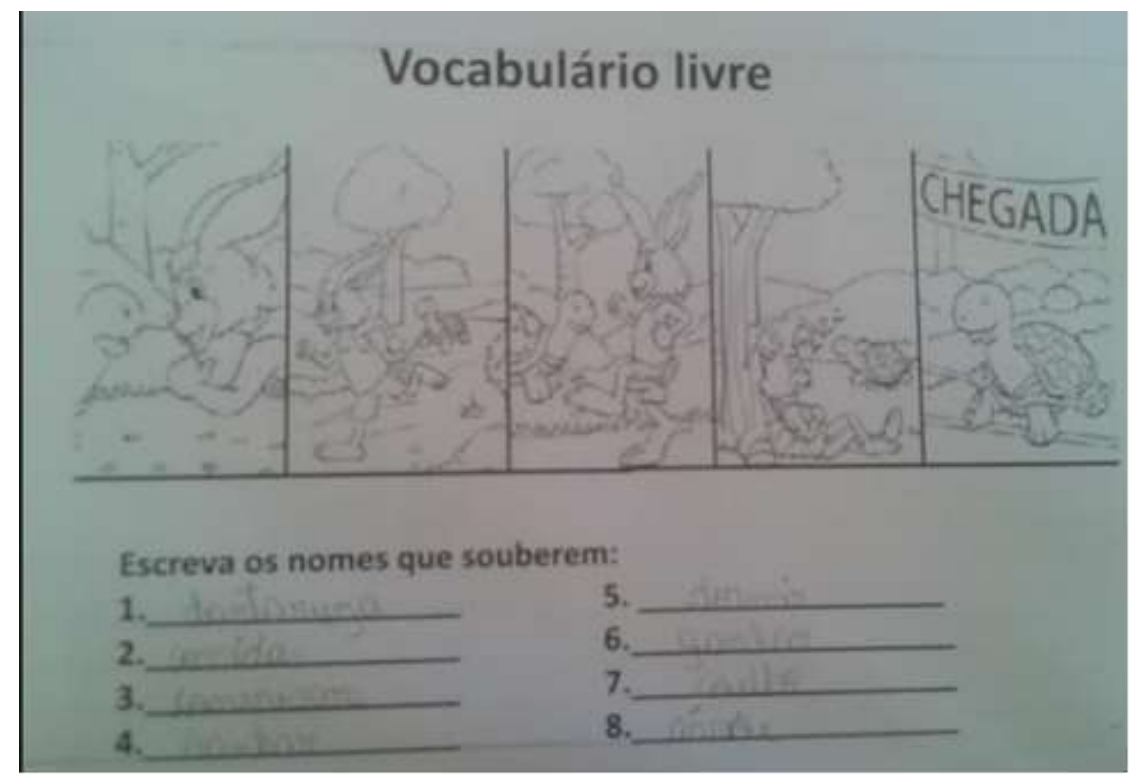

Figura 02- Vocabulário livre

Fonte: Moret (2016)

Como a identidade surda se constrói dentro da cultural visual, é fundamental que as atividades didáticas e pedagógicas sejam pensadas na perspectiva da cultural surda. Considera-se necessário que os processos de ensino e aprendizagem sejam integradores e significativos na cultura surda.

Assim após todo esse trabalho de ensino das palavras, era entregue a aluna as atividades correspondentes a cada texto.

\section{4․ ETAPA}

Nessa etapa foi realizada a nova aplicação do instrumental Provinha Brasil.

A aluna refez a avaliação sem a necessidade da interpretação literal da prova, pois conseguiu entender o que o enunciado solicitava. Diferente da aplicação inicial, nessa etapa não houve nervosismo e nem preocupação por parte da aluna, pois a mesma se sentiu confiante para responder toda a avaliação.

Nos fragmentos abaixo podemos ver a evolução da aluna, pois é feito a comparação da primeira aplicação do instrumental e da última: 


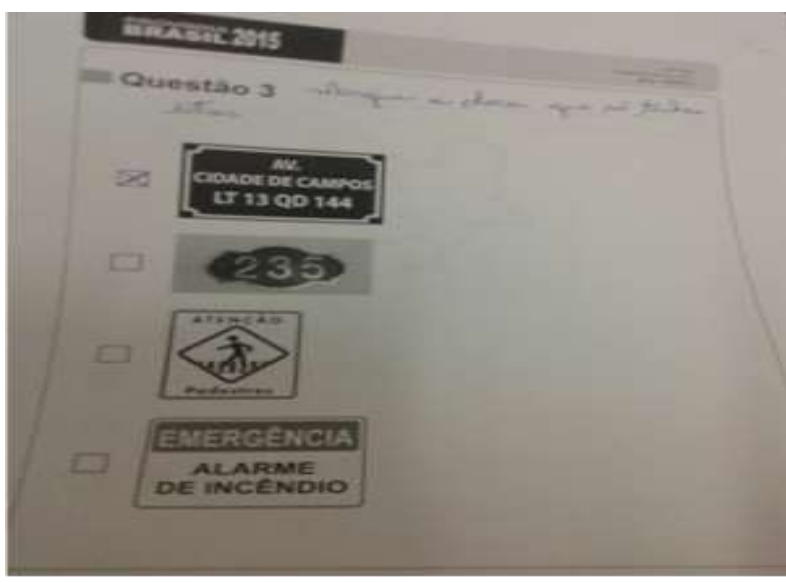

Figura 03- Fragmento da Provinha Brasil- 1a Aplicação Fonte: Moret (2016)

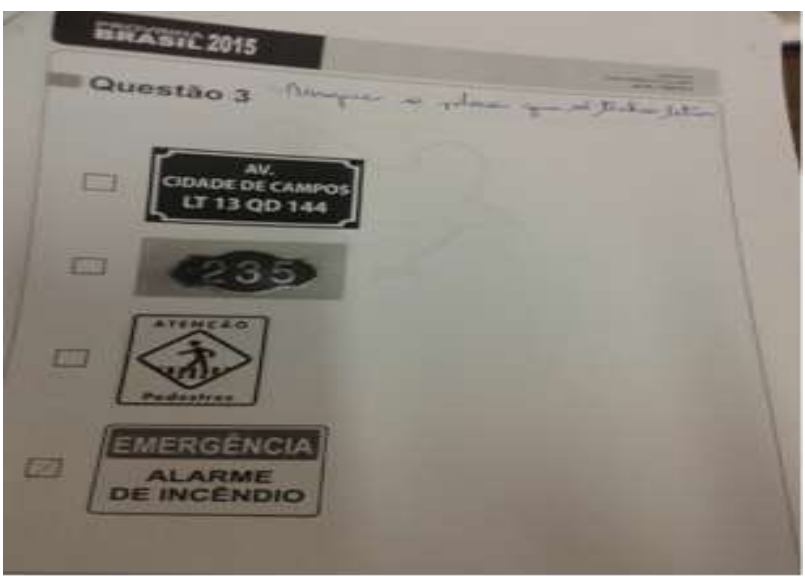

Figura 04- Fragmento da Provinha Brasil - 2a Aplicação Fonte: Moret (2016)

Nesses fragmentos é possível perceber que a aluna antes não tinha se quer a definição entre letras e números e após todo o trabalho da pesquisa-ação ela obteve um grande progresso, conseguindo entender essa diferenciação e assimilar novas palavras para seu vocabulário da língua escrita.

As evidencias comprovam essa melhora no processo de alfabetização, uma vez que antes usava apenas de hipóteses e agora usa de fato a leitura das palavras para responder.

\section{ETAPA}

Nessa etapa foi realizada a análise dos resultados da pesquisa-ação, onde pode-se constatar a evolução da aluna durante todo o processo de ensino.

Thiollent (1996, p.28) afirma que "a avaliação dos resultados de uma pesquisa-ação é efetuada pelos participantes e pelos pesquisadores. Os resultados são difundidos sem restrição. Uma das partes não pode pretender se apoderar deles exclusivamente", dessa forma, baseados nesse autor a equipe participante da pesquisa, chegou a consenso do crescimento alfabético da aluna e a decisão de continuidade dessa formação durante todo ano letivo de 2017 e 2018 até a conclusão do ensino médio pela aluna.

A aluna se sentiu motivada a dar sequência nos estudos, uma vez que terá oportunidade de igualdade. Ela afirma que buscará aprender a cada dia mais e que esse trabalho foi o ponta pé inicial para sua formação.

Thiollent (1996, p.25) diz: "com a pesquisa-ação pretende-se alcançar realizações, ações efetivas, transformações ou mudanças no campo social". Assim pode-se afirmar que essa pesquisa foi de grande relevância para aluna surda, uma vez ajudou minimizar muitas dificuldades no processo de alfabetização, além de melhorar a perspectiva da aluna, quanto sua formação. A mesma acredita que que conseguirá estar alfabetizada na $L 2$ antes de ingressar no ensino superior, pois esse trabalho iniciado em 2016 será levado adiante até a conclusão do ensino médio. Assim espera-se que essa problemática da alfabetização seja minimizada e que a mesma tenha mais qualidade em sua educação/formação.

Essa pesquisa foi muito importante para formação acadêmica da pesquisadora como também para comunidade surda de Colorado do Oeste e região, pois através desse trabalho podese evidenciar a eficácia da proposta bilíngue para alfabetização desses alunos, servindo de instrumento para outros alunos. 


\section{CONCLUSÃO}

Ao longo do trabalho foram apresentadas teorias e reflexão sobre o ensino da língua portuguesa para surdos como segunda língua, e evidenciado a aplicabilidade da proposta bilíngue para sua alfabetização. Apesar da proposta bilíngue estar idealizada pelo Decreto 5.626/05 ainda não é implantada nas escolas brasileiras, deixando o prejuízo aos alunos surdos matriculados, pois não obtêm resultados positivos na sua alfabetização e isso acarreta problemas durante toda sua formação.

Diante disso o presente trabalho apresentou etapas utilizadas para melhoria dessa realidade e resultados positivos durante toda ação, podendo servir de base para novos estudos e de ferramenta para o ensino da L2 para surdos, pois mostra estratégias e metodologias utilizadas nesse processo.

Durante a pesquisa-ação foi possível diagnosticar o planejamento do professore do AEE e fazer as adaptações necessárias, pois o planejamento não era adequado, verificando assim a falta da formação dos profissionais da sala multifuncional e demais professores que atuam com a aluna surda. Diante dessa realidade foi realizado um trabalho de formação para equipe do AEE uma vez que os demais professores não tinham condições de participar dessa formação, devido suas cargas horárias. Mas com a equipe do AEE tem ligação direta com os demais professores e conhecem a demanda da aluna, farão o intercambio desse aprendizado.

Outro diagnóstico realizado foi quanto ao nível de alfabetização da aluna surda que se encontra no nível silábico-alfabético, conhecendo poucas palavras, não tendo a noção básica entre números e letras, entre outros. E ao final obteve um resultado muito positivo, conseguindo evoluir seu nível para o alfabético e fazendo a distinção entre números e letras, aquisição de novas palavras, assimilação de palavras mais complexas, além de conseguir realizar leitura de textos pequenos com figuras.

Durante a pesquisa-ação foi atingido uma meta muito relevante para formação da aluna surda. Essa meta foi à reestruturação de um planejamento individual baseado na proposta bilíngue para alfabetização da aluna. Essa ação foi realizada em parceria com a equipe colaborada e servirá como base para os demais anos letivos, servindo de modelo para novos planejamentos.

As intervenções realizadas com aluna surda serviram para enriquecimento práticopedagógico de todos os colaboradores e pesquisadora, pois a cada encontro pode-se aprimorar novos saberes e conhecimentos a respeito do ensino da L2 para surdos, além também da gratificação pelo aprendizado da aluna.

Essa fase de intervenções foi de grande valia para toda equipe colaborativa, pois servirá de base para o ensino de novos alunos surdos que se matricularam na escola, pois sabemos que após a divulgação dos resultados alcançados nesta pesquisa, novos surdos terão interesse em estudar ou voltar para escola.

Durante toda a pesquisa-ação pode-se observar as principais dificuldades enfrentadas no processo de alfabetização da aluna surda, uma das mais relevantes é o atraso no processo, pois deveria ser realizado nos primeiros anos letivos da aluna e não agora nos últimos. Assim fica 
evidente que esse processo de alfabetização dos surdos deve ocorrer da mesma forma que é realizado com alunos ouvintes, já nos primeiros anos de ensino. Lembrando que esse processo deve ser baseado na proposta bilíngue, pois é a ideal e capaz de promover um verdadeiro aprendizado.

A proposta bilíngue foi desenvolvida em dois bimestres, equivalentes há 100 (cem) dias letivos, sendo trabalhado apenas uma vez por semana, e mesmo assim obtivemos muitos avanços e melhoria na alfabetização da aluna Bruna. Dessa forma devemos pensar que se essa proposta for trabalhada já nos anos iniciais de escolarização e em momentos específicos e com mais frequência, essa problemática da alfabetização será eliminada de uma vez na educação dos surdos e os mesmo terão oportunidades igual a sua formação.

$\mathrm{Na}$ implantação da proposta bilíngue foi visível o crescimento intelectual da aluna e sua evolução, pois conseguiu ler e entender o que estava no papel, coisa que antes não tinha muito significado.

A aluna conseguiu elevar seu nível alfabético e chegar a um bom resultado que foi a mudança de um nível para outro. Esses avanços ficaram evidentes nas leituras já realizadas de pequenos textos, enunciados, além da melhora no rendimento escolar, pois está motivada a aprender mais. Assim o trabalho não termina por aí, a equipe do AEE dará sequência no próximo ano letivo e sanará essa problemática na vida dessa aluna.

\section{REFERÊNCIAS}

ALMEIDA, É. V.; MAIA FILHO, V. (2013). Aprenda Libras com Eficiência e Rapidez - Volumes 1 e 2. Editora: Mãos e Sinais.

ALMEIDA, M. C. (2000). Saúde e reabilitação de pessoas com deficiência: políticas e modelos assistenciais. Tese de doutorado. FCM, UNICAMP.

BOTELHO, P. (2002). Linguagem e Letramento na Educação de Surdos - Ideologias e Práticas Pedagógicas, Belo Horizonte, Autêntica.

BOTELHO, P. (1999). Educação inclusiva para surdos: desmistificando pressupostos. In.: SEMINÁRIO DE EDUCAÇÃO INCLUSIVA NA PUC DE MINAS GERAIS, Comunicação oral. Disponível em: $<w w w . s o c i e d a d e i n c l u s i v a . p u c m i n a s . b r / a n a i s p d f / e d u c s u r d o s . p d f>$. Acesso em 20 de janeiro de 2017.

BRASIL. (1988). Constituição da República Federativa do Brasil de 1988. Disponível em: http://www.planalto.gov.br/ccivil_03/constituicao/constitui \% C3 \%A7ao.htm Acesso em: 10 jul. 2016.

BRASIL.(2002). Congresso Nacional. Lei 10.436/2002, 24 de abril de 2002. Dispõe sobre a Língua Brasileira de Sinais Libras e dá outras providências. Disponível em: <http://www.planalto.gov.br/ccivil_03/leis/2002//10436.htm>. Acesso: em 13 jul. 2016. 
BRASIL. (2005). Decreto № 5.626/2005, 22 de dezembro de 2005. Disponível em: <http://www.planalto.gov.br/ccivil_03/_ato2004-2006/2005/decreto/d5626.htm> Acesso em: 13 jul. 2016.

BRASIL. (2009). Resolução № 4 de 02 de outubro de 2009. Disponível em:

http://portal.mec.gov.br/dmdocuments/rceb004_09.pdf. . Acesso em 09. mar. 2017.

BRASIL. (1996). Lei de Diretrizes e Bases da Educação Nacional- LDB, 9.394 de 20 de dezembro de 1996. Disponível em: < http://www.planalto.gov.br/CCIVIL_03/leis/L9394.htm>. Acesso em 13.jul.2016.

BRASIL. (2005). Ministério da educação - Política de Inclusão. Disponível em:

<http://portal.mec.gov.br/seesp/arquivos/pdf/docsubsidiariopoliticadeinclusao.pdf.> Acesso em 13.jul.2016.

BRASIL. (1989). Ministério da educação - Lei 7.853 de 24 de outubro de 1989 Portadores de Deficiência. Disponível em: < <http://www.pge.sp.gov.br/centrodeestudos/bibliotecavirtual/dh/volume\%20i/deflei7853.htm.> Acesso em:28.jul.2016.

BRASIL. (2007). Ministério da Educação. Programa ética e cidadania: Construindo valores na sociedade. Inclusão e exclusão social. Modulo 4 - Inclusão Social. Brasília 2007. Disponível em: file:///C:/Users/74796674268/Downloads/4_inclusao_fasciculo.pdf>. Acesso em 13 jul.2016.

BRASIL. (2007).Ministério da Educação. Atendimento Educacional Especializado: Pessoa com Surdez. Brasília 2007. Disponível em: http://portal.mec.gov.br/seesp/arquivos/pdf/aee_da.pdf

BRASIL. (1996). Ministério da Saúde. Conselho Nacional de Saúde. Diretrizes e normas regulamentadoras sobre pesquisa envolvendo seres humanos. Resolução 196. 1996. Brasília: CNS; 1996.

BRASIL. (2012). Ministério da Saúde. Conselho Nacional de Saúde. Diretrizes e normas regulamentadoras sobre pesquisa envolvendo seres humanos. Resolução 466/12 de 12/12/2012. Brasília: CNS;2012.

BARRETO, M; BARRETO, R. (2012). Escrita de Sinais sem mistérios. Vol. 1. Belo Horizonte: Edição do Autor.

CAMPOS, S. R. L.; Kober, D. C.; Melendes, A. J. (2011). O recurso midiático como portador de texto no letramento de crianças surdas. In: LODI, A. C. B.; Harrison, K. M. P.; Campos; Leitura e escrita no contexto da diversidade. Editora Mediação, 4a ed, Porto Alegre.

COSTA, J. P. B. (2010). A educação do surdo ontem e hoje: posição sujeito e identidade. Campinas, SP: Mercado das Letras.

DALLAN, Maria Salomé Soares; MASCIA, Márcia A. A. (2010). A escrita de Libras (SignWriting): um novo olhar para o desenvolvimento linguístico do aluno surdo e para a formação do professor de línguas. In: CONGRESSO LATINO-AMERICANO DE FORMAÇÃO DE PROFESSORES DE LÍNGUAS, 3, São Paulo. Anais... São Paulo: Universidade de Taubaté, 2010, p. 1-15). Acesso em: 08 dez. 2016. 
Disponível em: <<http://escritades.dominiotemporario.com/doc/III_CLAFPL.pdf〉>.

DAMÁZIO, M. F. M. (2007). Atendimento Educacional Especializado: Pessoa com Surdez. Brasília: SEESP/MEC.

DORZIAT, A. (2009). O outro da educação: pensando a surdez com base nos temas Identidade/Diferença, Currículo e Inclusão. - Petrópolis, RJ: Vozes.

DUARTE, S. B. R. (2013, out-dez). Aspectos Históricos e socioculturais da população surda. 20 (4), p.1713-1734. Artigo Disponível em: www.scielo.br/pdf/hcsm/v20n4/0104-5970-hcsm-20-0401713.pdf. Acesso em: 20/05/2014.

FELIPE,T. (1989). Bilinguismo e Surdez. Trabalho de Linguística Aplicada. V.14. p.101-112.

FENES. (1995). Libras - Língua Brasileira de Sinais. Belo Horizonte.

FERREIRA BRITO, L. (1993). Integração social e educação de surdos. Rio de Janeiro: Babel.

FERREIRA BRITO, L. (2010). Por uma Gramática de Língua de Sinais. Rio de Janeiro: Tempo Brasileiro.

FERREIRO, E.; TEBEROSKY, A. (1986). Psicogênese da língua escrita. Tradução de Diana Myriam Lichtenstein et al. Porto Alegre: Artes Médicas.

FRANCO, M. A. S. (2005, dez). Pedagogia da pesquisa-ação. In: Educação e Pesquisa. São Paulo, 31(3).

GESSER, A. (2009). Libras? que língua é essa?. São Paulo: Parábola.

GIL, A. C. (1996). Como elaborar projetos de pesquisa. 3.ed. São Paulo: Atlas.

GIRAFFA, L. M. M.; SANTAROSA, L. M. C. e CAMPOS, M. B. (2017). SIGNSIM: uma ferramenta para auxílio à aprendizagem da língua brasileira de sinais. $V$ Congresso Iberoamericano de Informática Educativa, 2000. Disponível em <http://lsm.dei.uc.pt/ribie/d ocfiles/txt200372912341SIGNSIM.pdf>. Acesso em $18 \mathrm{fev.}$

GODOY, A. S. (1995, abril). Introdução à pesquisa qualitativa e suas possibilidades. In: Revista de Administração de Empresas. São Paulo: v.35, n.2, p. 57-63.

GOLDFELD, M. (1997). A criança Surda: Linguagem e Cognição numa Perspectiva Sócio Interacionista. São Paulo, Plexus.

KARNOPP, L. B. (2005). Diálogos traduzidos: leitura e escrita em comunidades de surdos. Cultura, Poder e Educação-Um debate sobre estudos culturais em educação. Canoas: Editora ULBRA.

KARNOPP, L. B. (2007). Comunidade de surdos: contribuições para a educação. In: III Encuentro Internacional de Investigadores de Políticas Linguísticas, Córdoba. III Encuentro Internacional de Investigadores de Políticas Linguísticas. Córdoba: Secretaria de Extensión y Relaciones Internacionales, 2007. p. 119-122. 
KARNOPP, L. B.; MACHADO, R. N. (2006). Literatura Surda: ver histórias em língua de sinais. In: 2 Seminário Brasileiro de Estudos Culturais em Educação, 2006, Canoas. 2 SBECE. Canoas: ULBRA. p. $1-13$

KARNOPP, L. B. (2006). Literatura surda. ETD: Educação Temática Digital, v. 7, p. 2.

KARNOPP, L. B. (2010). Produções culturais de surdos: análise da literatura surda. Cadernos de Educação (UFPEL), v. Ano 19, p. 155-174.

KARNOPP, L. B. (2010). Sinais e Olhares: Produções Culturais em Comunidades de Surdos. In: Enicéia Gonçalves Mendes; Maria Amélia Almeida. (Org.). Das Margens ao Centro: perspectivas para as políticas e práticas educacionais no contexto da educação especial inclusiva. São Paulo: Junqueira \& Marin, p. 291-300.

LACERDA, C. B. F.; SANTOS, L. F. (2014). Tenho um aluno surdo, e agora? São Carlos: EduFSCar.

LODI, Ana Claudia et al. (Org.s). (2015). Letramento, Bilinguismo e Educação de Surdos. Porto Alegre: Mediação.

LUDKE, M.; ANDRÉ, M. E. D. A. (1986). Pesquisa em Educação: abordagens qualitativas. São Paulo: EPU.

MANTOAN, M. T. E. (2003). Inclusão Escolar: O que é? Por que? Como fazer? São Paulo: Moderna. p. 13-20 e 27-34.

MARCONI, M. de A.; LAKATOS, E. M. (2002). Técnicas de Pesquisa. 5. ed. São Paulo: Ed. Atlas.

MANZINI, E. J. (2004). Entrevista Semi-estruturada: Análise de Objetivos e de Roteiros. Depto de Educação Especial do Programa de Pós Graduação em Educação, Universidade Estadual São Paulo (UNESP), Marília, SP.

MINAYO, M. C. S. (2012). Pesquisa Social: teoria, método e criatividade. 31.ed. Petrópolis, RJ: Vozes.

NEGRELLI, M. E. D.; MARCON, S. S. (2006). Família e Criança Surda. Revista: Ciência, Cuidado e Saúde. V.5. № 1 Maringá. Disponível em:

http://eduem.uem.br/ojs/index.php/CiencCuidSaude/article/viewFile/5146/3332. Acesso em 03/06/2016

PERLIN, G. (2005). Identidades surdas. In: SKLIAR, C. (Org.). A surdez: um olhar sobre as diferenças. Porto Alegre: Mediação, 1998. P.51-73.

PERLIN, G.; MIRANDA, W. (2003). Surdos: o Narrar e a Política. In: Estudos Surdos - Ponto de Vista. Revista de Educação e Processos Inclusivos, Florianópolis, UFSC/NUP/CED, n. 5.

PERLIN, G. T. T.; STROBEL K. (2006). Fundamentos da Educação de Surdos, Universidade Federal De Santa Catarina - UFSC, Florianópolis.

QUADROS, Ronice Müller de. (2008). Educação de Surdos: aquisição da linguagem. Porto Alegre: Artmed, 1997 - reimpressão. 
SÁ, Nídia Regina Limeira de. (2010). Cultura, poder e educação de surdos. São Paulo: Paulinas.

SACRISTÁN, J. G. Educação no Século XXI: A educação que temos, a educação que queremos. Cap. 2, p. 38-63. s/d.

SACKS, O. (1990). Vendo vozes. Rio de janeiro: Imago.

SILVA, T. T. (1999). Documentos de identidades, uma introdução às teorias do currículo. Belo Horizonte, Autêntica,.

STROBEL, K. L. \& FERNANDES, S. (2008). As Imagens do outro sobre a Cultura Surda. Florianópolis, Ed. Da UFSC,

STUMPF, M. R. (2009). Escrita de Sinais II. Florianópolis,. Disponível em:

http://www.libras.ufsc.br/colecaoLetrasLibras/eixoFormacaoEspecifica/escritaDeSinaisll/assets/4 92/TEXTO-BASE_EscritaSinais2.pdf. Acesso em 06.03.17.

SKLIAR, Carlos (ORG.) (2013). A surdez: um olhar sobre as diferenças. 6o ed. Porto Alegre: Mediação. 